\title{
Disposal Criticality Analysis for Immobilized Pu: External Configurations
}

Peter Gottlieb (TRW), Sedat Goluoglu (Framatome Cogema Fuels)

and Paul L. Cloke (SAIC)

Civilian Radioactive Waste Management System, Management and Operating Contractor 1180 Town Center Drive

Las Vegas, NV 89134

(702)295-4381 / (702)295-5004 / (702)295-4476

\section{Introduction}

The problem of potential external criticality is defined according to the following features and issues:

- The environment outside the waste package is most conveniently divided into 3 zones: (1) Near-field, in the drift, external to the waste package; (2) Near far-field, several meters into the host rock immediately adjacent to the drift; (3) Far far-field, everything beyond the near far-field. These zones have different mechanisms for accumulating a critical mass from the passing waste package outflow.

- Fissile material can be transported outside of the waste package thereby becoming separated from the neutron absorber.

- Descriptions of uranium mineral deposits imply that concentrations sufficient for criticality can be accumulated by natural processes, particularly if the uranium is highly enriched. 
- Some configurations of fissile material in the external environment have been identified as having the potential for autocatalytic criticality behavior, but without examining the likelihood of the processes necessary to achieve such configurations.

The following factors limit the possibility of external criticality

- Absence of geologic formations in Yucca Mountain which can cause sufficient concentration

- Length of time required to form the typical geologic mineral deposit.

\section{Approach}

The following outlines the technical approach:

- Follow the geochemical analysis of the methodology paper, beginning with the estimation of the source term of fissile material flowing out of the waste package.

- Evaluate the maximum concentrations that can be accumulated by precipitation or adsorption on the fracture walls or in the voidspaces of the near field.

- Examine geologic literature on the possible occurrence of potentially concentrating formations in Yucca Mountain or similar geologic provinces (far field).

\section{Analysis and Results}

The following are the highlights of the analysis of potential deposition mechanisms for the near-field and near far-field:

- Trapping of particles of fissile material in the voidspaces can penetrate for only a few centimeters into the rock beneath the invert, because relatively large particles will plug the narrow aperture fractures. 
- Only the high $\mathrm{pH}$ outflow has any significant reaction with the rock, or any significant concentration of $\mathrm{U}$ or $\mathrm{Pu}$, but the precipitates from such reactions are dominated by other, non-fissile, elements.

- Smectite clay has some sorption capability, but not sufficient to accumulate a critical mass.

- Zeolites have some capacity for sorbing uranium, but evaluation of the experimental data on the maximum concentration achievable by such sorption, and reviewing the maximum concentrations found in the geologic literature, strongly indicates that this mechanism cannot produce a critical mass.

Although the above geochemistry analyses indicate that none of the proposed mechanisms are capable of accumulating a critical mass in the near field, it is useful to estimate how far critical parameters must be stretched beyond the calculated theoretical maximum in order to achieve a critical mass. For this purpose the following worst-case assumptions are made: (1) A major fraction of the outflow from a waste package is concentrated beneath one end of the waste package in a surface footprint of a 1 meter square; (2) The voidspace available for transport and precipitation in the invert and rock beneath the waste package is represented by a three dimensional fracture network having $0.1 \mathrm{~mm}$ aperture with a $3 \mathrm{~cm}$ spacing between fractures; (3) The flow containing fissile material has $\mathrm{pH}=10$, a uranium concentration equal to the solubility limit at that $\mathrm{pH}$, and can penetrate at least 1 meter beneath the surface without plugging. In such a configuration, criticality can occur if $1 \%$ of the fracture aperture volume is filled with an equivolume mixture of ${ }^{235} \mathrm{U}$ soddyite and $\mathrm{PuO}_{2}$, while the theoretical geochemistry 
calculations showed a maximum fracture filling of $0.06 \%$ by a mixture of $\mathrm{Pu}$ and ${ }^{235} \mathrm{U}$ bearing minerals (Ref. 1, Table 6.1-2), which implies a criticality safety factor of approximately $17 x$.

Analysis of potential accumulation mechanisms for the far far-field shows that the principal geologic formations with potential for accumulating a critical mass fall into the category of reducing zones. The following is a list of such formations and the reasons for their being highly unlikely at Yucca Mountain:

- Hydrothermal fluid: no evidence of recent volcanic activity .

- Organic material: Franklin Lakes Playa, 10 miles from Yucca Mountain, is the closest significant organic deposit, but it would take over $1,000,000$ years to accumulate a critical mass, since the fissile material transport would be significantly retarded by partially sorbing rock.

- A high-permeability channel could provide a faster path, but for only a fraction of the fissile material required for a critical mass.

\section{Conclusions}

- No external criticality is possible from any of the concentration mechanisms in the near field.

- Since the composition of the far field is not completely known, it is possible that there are formations which could serve as concentrators, but they are not likely to be found in Yucca mountain. 
- No criticality possibilities have been identified thus far, but if there were any they could be negated by the use of DU filler in the invert.

- Cumulative effects from multiple waste packages have been considered and shown to not significantly effect the above findings because the worst case accumulation in local geologic features could saturate the accumulation capability of the invert and the immediately adjacent rock with the contents of a single waste package, and such a worst case has already been reflected in the above findings.

\section{Acknowledgement}

This work was supported by the U. S. Department of Energy, Yucca Mountain Site Characterization Office as part of the Civilian Radioactive Waste Management Program

\section{References}

1. Report on External Criticality of Plutonium Waste Forms in a Geologic Repository, CRWMS M\&O, DI\#BB100000000-01717-5705-00018 REV 00, November 1997. 